\title{
Dark Period Following UV-C Treatment Enhances Killing of Botrytis cinerea Conidia and Controls Gray Mold of Strawberries
}

\author{
Wojciech J. Janisiewicz, Fumiomi Takeda, D. Michael Glenn, Mary J. Camp, and Wayne M. Jurick II
}

First, second, and third authors: U.S. Department of Agriculture, Agricultural Research Service (USDA-ARS), Appalachian Fruit Research Station, 2217 Wiltshire Road, Kearneysville, WV 25430; forth author: USDA-ARS, Statistics Group, Northeast Area, Beltsville, MD 20705; and fifth author: USDA-ARS, Henry A. Wallace Beltsville Agricultural Research Center, Food Quality Laboratory, Beltsville, MD 20705. Accepted for publication 21 December 2015.

\begin{abstract}
Janisiewicz, W. J., Takeda, F., Glenn, D. M., Camp, M. J., and Jurick, W. M., II. 2016. Dark period following UV-C treatment enhances killing of Botrytis cinerea conidia and controls gray mold of strawberries. Phytopathology 106:386-394.

Strawberries are available throughout the year either from production in the field or from high and low tunnel culture. Diversity of production conditions results in new challenges in controlling diseases before and after harvest. Fungicides have traditionally been used to control these diseases; however, their limitations necessitate a search for new approaches. We found that UV-C irradiation of Botrytis cinerea, a major pathogen of strawberry, can effectively kill this fungus if a dark period follows the treatment. The inclusion of a 4-h dark period resulted in almost complete kill of $B$. cinerea conidia on agar media at a dose of $12.36 \mathrm{~J} / \mathrm{m}^{2}$. The UV-C dose did not cause a reduction in photosynthesis in strawberry leaves or

discoloration of sepals, even after exposing plants repeatedly (twice a week) for 7 weeks. Although irradiation of dry conidia of $B$. cinerea with this dose resulted in some survival, the conidia were not infective and not able to cause decay even when inoculated onto a highly susceptible mature apple fruit. Irradiation of strawberry pollen at $12.36 \mathrm{~J} / \mathrm{m}^{2}$ did not affect pollen germination, tube growth and length in vitro, or germination and tube growth in the style of hand-pollinated emasculated strawberry flowers. No negative effect of the UV-C treatment was observed on fruit yield and quality in high tunnel culture. In the fruit and flower petal inoculation tests, the UV-C treatment was highly effective in reducing fruit decay and petal infection. This UV-C treatment with an exposure time of $60 \mathrm{~s}$ may be useful in controlling gray mold in tunnel production of strawberries and may also have the potential for use in intensive field and indoor production of other fruits and vegetables providing that a 4 -h dark period follows the irradiation.
\end{abstract}

Strawberry fruit are currently available year round due to increased production in protective culture such as high tunnels before and after the field season. Diseases such as gray mold (caused by Botrytis cinerea), anthracnose (caused by Colletotrichum acutatum), or powdery mildew (caused by Podosphaera aphanis) can cause severe losses by reducing yield and causing fruit decay during production and after harvest, if not controlled beginning early on in the production cycle (Burlakoti et al. 2013; Carisse et al. 2013; Smith 2013; Xiao et al. 2001). For control of gray mold it has been paramount that the control measures begin in the field at bloom, to protect flowers from infections that may account for nearly $80 \%$ of fruit decay after harvest (Bulger et al. 1987). Fungicides have been traditionally used for controlling these diseases starting with application at early flowering stage until harvest in regular intervals (Bulger et al. 1987; Mertely et al. 2002; Wedge et al. 2007; Wilcox and Seem 1994). However, their use in high tunnel culture introduces an additional problem by requiring time periods between the application of a fungicide and reentry into the tunnels. This can interfere with harvest, which could be as frequent as every other day. Additionally, the development of resistance to fungicides in major pathogens necessitates exploring novel control

Corresponding author: W. J. Janisiewicz;

E-mail address: Wojciech.Janisiewicz@ars.usda.gov

*The $\boldsymbol{e}$-Xtra logo stands for "electronic extra" and indicates that four supplementary figures are published online.

http://dx.doi.org/10.1094/PHYTO-09-15-0240-R

This article is in the public domain and not copyrightable. It may be freely reprinted with customary crediting of the source. The American Phytopathological Society, 2016. strategies (Smith 2013; Wedge et al. 2007). The constant threat of new regulations limiting the use of pesticides, especially in protected culture, and an increasing market demand for fruit free of pesticides further necessitates the search for alternatives to synthetic fungicides (Hanson et al. 2013; Offner 2013; Vorstermans and Creemers 2011). Integrated pest management and biological control in high tunnel production has made significant progress during the past decades (Picket-Pottorff and Panter 2009); however, more research is needed to reduce losses and make this system more profitable.

Biological approaches to control strawberry diseases have been explored with considerable success. However, biological control alone is not as effective as conventional fungicide treatments (Bhatt and Vaughan 1962, Karabulut et al. 2004; Lima et al. 1997; Peng et al.1992; Pertot et al. 2008; Sylla et al. 2013; Xu et al. 2010). Despite growers positive attitudes toward the idea of using biocontrol agents in strawberry fruit production in the main growing areas of Germany, Italy, and Israel, commercial biocontrol products have been used rarely in strawberry production (Moser et al. 2008). Combining biological control with compatible physical or chemical treatments has been very successful in increasing the effectiveness of disease control, especially on fruit after harvest (Janisiewicz and Conway 2011).

UV-C has been used to kill microorganisms in various systems including the sterilization of air in hospitals, water in treatment plants, and to some extent in agriculture and the food industry (Bachmann 1975; Beggs et al. 2006; Bintsis et al. 2000; Gardner and Shama 2000; Hijnen et al. 2006; Schenk et al. 2012). Postharvest treatment of potatoes, carrots, tomatoes, bell peppers, table grapes, strawberries, apples, peaches, and citrus fruit with UV-C induced resistance to decay-causing fungi in these commodities, resulting in reduction of decay (Adrian et al. 2000; Chalutz et al. 1992; Charles et al. 1999; Droby et al. 1993; Mercier et al. 2000; Nigro et al. 1998, 2000; Stevens et al. 1990, 1998; Wilson et al. 1994). Treatment of 
harvested strawberries with UV-C alone or with pulsed white light and heat significantly reduced decay in storage (Marquenie et al. 2003; Nigro et al. 2000; Van Delm et al. 2014). A combination of UV-C and heat allowed for a reduction in intensity of the treatments for inactivation of Botrytis cinerea and Monilinia fructicola conidia (Marquenie et al. 2002b). Treatment of apple slices with UV-C was more effective in controlling foodborne pathogens such as Escherichia coli, Listeria innocua, or Salmonella enterica than conventional treatment with sodium chloride and had no negative effects on the quality of the slices (Graça et al. 2013). Treatment of leafy vegetables such as spinach or lettuce with UV-C has also been effective in reducing populations of foodborne pathogens and other bacterial microflora; however, higher doses that reduced most of the populations caused softening of the tissue (Allende et al. 2006; Escalona et al. 2010). Ultraviolet irradiation of Botrytis fabae, a fungal pathogen of beans (Vicia faba), reduced conidia infectivity more rapidly than their viability, as determined by growth on agar media (Buxton et al. 1957). Also, an exposure to light after irradiation reduced the effect of ultraviolet treatment (Last and Buxton 1955). Despite the considerable potential benefits of using UV-C for controlling various diseases this approach has only been used sporadically under commercial conditions. It appears that a damaging effect to plants at doses required to kill a substantial portion of the pathogen population coupled with a limited and variable effect of UV-C on the induction of resistance in fruit have limited the use of this technology.

Here we report on the strong increase in killing power of the UV-C $(254 \mathrm{~nm})$ treatment against $B$. cinerea by including a dark period after the irradiation. To test the potential usefulness of this approach, we evaluated the possibility of any deleterious effects of the UV-C irradiation levels at the pathogen killing dose on strawberry pollen viability, tube growth, fruit set, strawberry leaf photosynthesis system as well as reduction of flower and fruit infection under laboratory conditions. We also conducted a preliminary test to determine any potential negative effect of the UV-C treatment on fruit yield and quality in high tunnel.

\section{MATERIALS AND METHODS}

Pathogen. B. cinerea (isolate J4) was originally isolated from a decayed apple fruit and was used in previous studies on pome fruits and strawberries because it is one of the most aggressive isolates in our collection. Conidia of B. cinerea were collected from 10- to 14day-old cultures grown on potato dextrose agar (PDA) by a handheld vacuum powered cyclone spore collector (Geoff Harms, Physics Laboratory, University of Minnesota, St. Paul, MN), resuspended in sterile distilled water (SDW), sonicated for $60 \mathrm{~s}$ to separate individual conidia, vortexed, and adjusted to desired concentrations using a hemacytometer.

Plants. Strawberry plants 'Albion' and 'Monterey' are dayneutral cultivars released in 2006 and 2009, respectively, by the University of California (Shaw and Larson 2006, 2009) and were used in the experiments. Cold-stored, bare-root strawberry plants were obtained from a commercial nursery (Lassen Canyon Nursery, Redding, CA) and transplanted into $16.25 \mathrm{~cm}$ (6.5 in.) standard TEKU round pots filled with PRO-MIX peat-based growing media (Hummert International, Earth City, MO). Plants were maintained on a greenhouse bench from September to March with monthly applications of Scotts Osmocote Plus slow-release fertilizer, supplemented with Fe-EDDHA. Plants were watered as needed, and flowers and runners were removed at 2-week intervals. In March, potted plants were moved into two modified, $3.6 \mathrm{~m}$ (length) $\times 2.4 \mathrm{~m}$ (width) $\times 2.2 \mathrm{~m}$ (height) day-lit walk-in growth chambers (Environmental Growth Chambers, Chagrin Falls, OH), clad in $1.2 \mathrm{~cm}$ (1/2 in.) twin-wall Plexiglass panels. The temperatures in the chamber were maintained at $20 \pm 3^{\circ} \mathrm{C}$ during day and $16 \pm 3^{\circ} \mathrm{C}$ at night. Plants were irrigated with a drip line daily from 15 to $45 \mathrm{~min}$. For experiments in tunnel, potted plants were transferred into a high tunnel $(6.8 \mathrm{~m} \times 25.5 \mathrm{~m})$ covered with a polyethylene film and $1.5-\mathrm{m}$ high side vents (Ledgewood Farm Greenhouse, Moultonborough, NH) where they were set $27.5 \mathrm{~cm}$ apart in a two-row configuration on top of $60-\mathrm{cm}$ wide perlite filled beds. Chemicals Brigade (WSB bifenthrin) and Marathon II (imidacloril), and release of predators Amblyseius cucumeris, Orius insidiosus, and Neoseiulus californicus (Beneficiary Insectary, Redding, CA) were used to control insects and mites. Fungicides were not applied to plants in the growth chambers or to plants designated for UV-C irradiation treatments.

UV-C irradiation unit. All UV-C irradiation was conducted with lamps having a peak emission at $254 \mathrm{~nm}$ (model TUV PL-L 55 Watt; Phillips North America Corp., Andover, MA). The lamp was mounted on a frame that allowed for the adjustment of a distance to the targeted irradiation surface (plates or plants) to $30 \mathrm{~cm}$. This distance was selected because it reflects the parameters in the future design of a commercial irradiation apparatus. The frame was enclosed to prevent any light penetration of the enclosure. The UV-C lamp was turned on at least $10 \mathrm{~min}$ prior to irradiation to ensure consistent intensity levels. The irradiation intensity at the distance of $30 \mathrm{~cm}$ was $0.206 \mathrm{~W} / \mathrm{m}^{2}$ $\left(20.6 \mu \mathrm{W} / \mathrm{cm}^{2}\right)$. Thus, the $60 \mathrm{~s}$ illumination corresponded to $12.36 \mathrm{~J} / \mathrm{m}^{2}$ $\left(0.001236 \mathrm{~J} / \mathrm{cm}^{2}\right)$. Irradiance was measured with a calibrated spectrometer (StellarNet Inc. EPP2000, Tampa, FL).

Irradiation of conidia. A conidial suspension adjusted to $1 \times$ $10^{4}$ conidia/ml was vortexed thoroughly, and an aliquot of $25 \mu \mathrm{l}$ was spread onto $5 \mathrm{~cm}$ PDA plates. Plates were placed on a tray and after the liquid was absorbed by the medium (approximately 15 to $20 \mathrm{~min}$ ), the lids from the plates were removed and the tray was placed under UV-C light at a distance of $30 \mathrm{~cm}$. After exposure to UV-C for 30 or $60 \mathrm{~s}$, the tray was removed, the lids were placed back on the plates, and the plates were sealed with Parafilm and either placed immediately in light or incubated in dark for various periods of time before exposing to continuous light at $25^{\circ} \mathrm{C}$.

Plates with $B$. cinerea conidia were examined for the presence of B. cinerea colonies after 24 and $48 \mathrm{~h}$ of incubation. No additional colonies were observed after longer incubation. There were three plates per treatment and each plate constituted a single replicate. The plates were arranged in a random fashion. The experiment was repeated twice.

Irradiation of dry conidia of $B$. cinerea was conducted similar to pollen irradiation, described below, except that the conidia were deposited on the Petri plates in a very thin layer by gently shaking the spore collector tube. After irradiation treatments, the conidia were collected in sterile tap water (STW), and the concentration was adjusted to $1 \times 10^{4}$ conidia/ml with a hemacytometer before they were plated on PDA or used for fruit inoculation. The experiment was repeated.

Irradiation of strawberry plants. To determine any potential negative effects of UV-C exposure on strawberry plants, in a preliminary experiment, potted plants were exposed to UV-C doses of 0,30 , and $60 \mathrm{~s}, 2,3,4,5,10,20,30,40,50$, and $60 \mathrm{~min}$ followed by a 4-h dark period in the irradiation room, and then maintained in a greenhouse. Also, longer exposures to UV-C for 2,4 , and $6 \mathrm{~h}$ were used to determine the levels of chlorophyll degradation after extensive exposures to UV-C. The plants were subjected to chlorophyll degradation analysis using Imaging-PAM Chlorophyll Fluorometer System (Heiz Walz GmbH, Effeltrich, Germany) with ImagingWin v2.40b software before and at various intervals after irradiation. The Maximal Photosynthesis II Quantum Yield (Fv/Fm) was determined at chlorophyll resting stage. After the preliminary test with a single plant per treatment, a full-scale experiment was conducted with UV-C irradiation for 0,30 , and $60 \mathrm{~s}$ followed by a 4-h dark period twice a week for 7 weeks, where each potted plant constituted a single replicate and there were three replicates for each treatment.

Effects of UV-C on strawberry pollen viability, germination, and tube growth. Pollen collection and irradiation. Fully opened flowers with bright yellow anthers were collected from several plants in greenhouse culture. The anthers were removed using sterile forceps and placed in a Petri plate $(10 \mathrm{~cm}$ in diameter) overnight to promote dehiscence, and the plate was agitated to release pollen from the anthers the following day. The anthers 
were removed and the collected pollen was mixed to create a homogenous blend. The pollen was divided among multiple $5 \mathrm{~cm}$ Petri plates to accommodate the number of treatments and there were three one-plate replicates per treatment.

Lids from the $5 \mathrm{~cm}$ plates containing pollen were removed and placed next to the opened plates with the inside surface facing the UV-C bulb at a distance of $30 \mathrm{~cm}$, and irradiated for the designated time. After UV-C exposure, the plates were either placed immediately in the light or in plastic boxes, wrapped with black plastic, and incubated in total darkness at $22^{\circ} \mathrm{C}$ for up to $6 \mathrm{~h}$. Plates were removed at 1-h intervals and the pollen then was spread on glass microscope slides for the viability, germination, and tube growth study as described below. The pollen from the 4-h dark incubation also was used to pollinate emasculated strawberry flowers in in situ pollen germination and tube growth experiments as described below.

Pollen viability. Viability of both control and UV-C exposed pollen was assessed by fluorescent staining with $10 \mu \mathrm{M} \mathrm{H}_{2}$ DCF-DA (Sigma, St. Louis, MO) in dimethyl sulfoxide (DMSO). Pollen from plates was collected with an inoculation loop and moved to a vial containing $1 \mathrm{ml}$ of the stain solution and incubated for $10 \mathrm{~min}$ in darkness. The stain was centrifuged at $14,655 \times g$ for $60 \mathrm{~s}$, the supernatant was discarded, and the pollen was resuspended in $500 \mu \mathrm{l}$ of SDW to wash any remaining stain, centrifuged again $(14,655 \times g)$ for $60 \mathrm{~s}$, resuspended in $100 \mu \mathrm{l}$ of SDW, and then paced on glass slides and examined microscopically (Zeiss Axiophot). Several random view fields were selected to count 100 pollen grains. There were three one-microscopic slide replicates per treatment and the experiment was repeated. Grains were rated as viable if they fluoresced under UV illumination and the count was compared with the examination of the same view under bright field illumination that included all pollen grains, viable and nonviable.

In vitro pollen germination and tube growth. An aliquot of $100 \mu \mathrm{l}$ of pollen-germination solution (10\% sucrose and $0.01 \%$ $\mathrm{H}_{3} \mathrm{BO}_{3}$ ) was added to each of the pollen-coated microscope slides that were either irradiated with UV-C for $60 \mathrm{~s}$ or not irradiated and kept in the dark for $4 \mathrm{~h}$ immediately after the treatment. The slides were incubated in Petri plates with moistened filter paper overnight at $25^{\circ} \mathrm{C}$. Then the pollen was stained with lactophenol cotton blue and examined microscopically. Several random view fields were examined and 100 pollen grains per replicate were rated on a 4-point scale: $1=$ not germinated, $2=$ pollen tube length $<2 \times$ pollen diameter, $3=$ pollen tube length $2 \times$ to $4 \times$ pollen diameter, and $4=$ pollen tube length $>4 \times$ pollen diameter. There were three replicates per treatment. Pollen from the same batch was also used in a subsequent experiment where the pollen tube length was measured using the "polyline" tool in the DP2-BSW software for the Olympus DP71 microscope digital camera (Olympus America Inc., Center Valley, PA). One hundred pollen tubes were measured per replicate. There were three replicates per treatment.

In situ pollen germination and tube growth. Strawberry flowers were emasculated by removing the anthers from the filaments of newly opened blooms maintained in high tunnel culture. The anthers and pollen were collected as stated above. Emasculated flowers were marked and covered with brown paper bags to prevent natural pollination. The pollen was exposed to UV-C $(254 \mathrm{~nm})$ treatment and kept in the dark for $4 \mathrm{~h}$. Nontreated control pollen and UV-C-treated pollen was spread on the stigmas of separate emasculated flowers using a sterile glass rod. Then the flowers were covered with the brown paper bags again. The flowers were detached after $24 \mathrm{~h}$ and brought into the laboratory for microscopic observation. The styles and attached ovaries were carefully separated from the flower receptacle, placed on glass slides, and stained with $0.1 \%$ aniline blue in phosphate buffer, $\mathrm{pH} 7.4$, for at least $10 \mathrm{~min}$. A coverslip was placed on top and gently pressed with a pencil eraser to facilitate stain penetration by splitting of the style. Specimens were observed under UV illumination using the Zeiss Axiophot microscope, and the images of the growing pollen tube were captured with an Olympus DL71 microscope digital camera.
Infectivity of the irradiated dry conidia. To determine if viable UV-C exposed conidia of $B$. cinerea could cause fruit decay, we used apple as a model system because wounds of mature apples are very susceptible to $B$. cinerea infection and the wound size and volume of the inoculum applied can be well standardized. Also, the resulting fruit decay is easy to observe and discernible from decays caused by other pathogens. Mature 'Golden Delicious' apples were surface-sterilized with $70 \%$ ethanol and allowed to dry under a transfer hood to prevent contamination. Apples were wounded in four places with a cylindrical tool ( $3 \mathrm{~mm}$ diameter and $3 \mathrm{~mm}$ deep), the cut tissue was removed, and the wounds were inoculated each with $25 \mu \mathrm{l}$ of $1 \times 10^{4}$ conidia/ml suspension made from the dry conidia exposed to different levels of UV-C irradiation. Inoculated fruit were placed in closed boxes and incubated at $22^{\circ} \mathrm{C}$ for 5 days. There were four replicate fruit for each set of treatments.

Fruit wounding, inoculation, and irradiation. Strawberry fruit were harvested from multiple 'Monterey' strawberry plants maintained in greenhouse culture on the day of the experiment, randomized and placed on top of $5 \mathrm{~cm}$ plastic Petri plate lids, and arranged in groups of three in $15 \mathrm{~cm}$ glass Petri plate lids for wounding, inoculation and UV-C treatment. Each group of three fruit in one $15 \mathrm{~cm}$ lid was considered a replicate. There were three replications per treatment and the experiment was repeated. Fruit were gently wounded with fine-grit sandpaper just enough to break the surface of the berry. Wounded fruit were misted with either STW for control treatments or with a suspension of B. cinerea $\left(1 \times 10^{4}\right.$ conidia $/ \mathrm{ml}$ ). After inoculation, fruit were allowed to air dry for approximately $20 \mathrm{~min}$ prior to UV-C treatment. For UV-C treatments each replicate was placed under the UV-C bulb at a distance of $30 \mathrm{~cm}$ and irradiated for the designated time. Irradiated and notirradiated dishes (replicates) with fruit were placed in plastic boxes, covered with lids, and incubated in total darkness at $22^{\circ} \mathrm{C}$ for $4 \mathrm{~h}$. After incubation in the dark, each replicate was then covered with a high glass dish cover and incubated in the humid environment for 7 days. Incidence of infection was determined after 3, 5, and 7 days.

Petal inoculation and irradiation. Since as much as $80 \%$ of pre- and postharvest strawberry fruit decays originate from flower infection, a flower petal test was developed to determine the effect of the UV-C irradiation treatment on petal infection by $B$. cinerea. Strawberry flowers were harvested from multiple 'Monterey' plants in greenhouse culture and placed in small glass culture tubes with water. Flowers were misted with either SDW or the suspension of B. cinerea conidia $\left(1 \times 10^{4}\right.$ or $1 \times 10^{5}$ conidia/ml $)$ and allowed to air dry for approximately $30 \mathrm{~min}$. Petals were carefully removed with forceps and placed onto glass microscope slides (three petals per slide for each of four replicates). Slides were placed on top of glass rods in glass Petri plates lined with moistened filter paper. For UV-C treatments, opened plates with the slides were placed under the UV-C bulb at a distance of $30 \mathrm{~cm}$ and irradiated for $60 \mathrm{~s}$. Then the irradiated and nonirradiated plates were covered with lids and placed in covered plastic boxes and incubated in total darkness at $22^{\circ} \mathrm{C}$ for $4 \mathrm{~h}$. After the dark incubation period, plates were removed from plastic boxes and kept on the laboratory bench for 5 days incubation. Incidence of infection based on browning of the petals was recorded after 3 and 5 days. The experiment was repeated.

Preliminary tests in high tunnel. $U V-C$ apparatus. The UV-C apparatus was designed and built on site at USDA-ARS Appalachian Fruit Research Station in Kearneysville, WV. It consists of a steel frame on three wheels (one in the center front and two on the sides) with four UV-C light fixture boxes mounted facing the ground and spread evenly on the frame to cover four raised beds with strawberry plants (Supplementary Fig. S1). Power to the electrical motor moving the frame is controlled by a master timer that can be set for a chosen time of day. One limit switch mounted near the front wheel activates multiple other time delay relays that control the motor stop time duration as well as the duration of UV-C irradiation for each of the four light fixtures. 
$U V-C$ irradiation in tunnel. The main purpose of this preliminary test was to determine if there are any negative effects of UV-C irradiation on fruit set, yield, and quality. Prior to planting potted strawberry plants ('Albion'), the tunnel was without any plants for over 6 months and the beds were prepared with fresh vermiculate, which eliminated any primary inoculum of strawberry diseases. This assured that at least at the early phase the disease development will be low and will not interfere much with the effect of the UV-C irradiation of the fruit yield and quality. All runners, fruit, and flowers were removed from the plants prior to start of UV-C exposure course. Each row had designated exposure duration $(0,30$, or $60 \mathrm{~s})$ followed by a dark period. There were five plots per row, each treated as a single replicate. At the end of each row there were plots with fungicide treatments (weekly application) of Captan 50WP plus either Cabrio EG (pyraclostrobin), Pristine WG (boscalid and pyraclostrobin), or Elevate 50WDG (fenhexamid) in rotation at manufacturer's recommended concentrations. To irradiate strawberry plants, at the end of work day, the timer was set for 11:00 P.M. to turn on the master power switch that activated the main motor moving the frame and individual timers controlling the duration of UV-C exposure from each box. The UV-C treatment to all plots took less than $15 \mathrm{~min}$, thus leaving more than an adequate dark period during the rest of the night. The UV-C treatments were administered twice weekly on Monday and Thursday nights. Harvests began 3 week after the first UV-C treatment and were performed each Monday and Thursday for five consecutive weeks. Fruit were visually assessed for ripeness based on the uniformity of color of the berry. Ripe fruit were cut from the plant leaving approximately $1 / 4$ inch stem attached and placed in labeled weigh boats. Both healthy and diseased fruit were harvested. Fruit from each treatment replicate were counted and weighed and the values were recorded. Each fruit was then assessed as diseased or healthy and either well-shaped or deformed, and fruit counts and weights by category were recorded.

Data analysis. All in vitro and in situ experiments were set up in completely randomized design. Each treatment within an experiment was replicated at least three times and experiments with the exception of the preliminary test were repeated with similar results at least once. The data analysis was conducted using SAS/STAT 14.1 (SAS Institute Inc., Cary, NC) or StatXact 10: Statistical Software for Exact Nonparametric Inference (Cytel Software Corp., Cambridge, MA).

The $B$. cinerea colony count at $48 \mathrm{~h}$ after exposure to UV-C was analyzed as a two-factor linear model with incubation in the dark and UV-C exposure as the factors using PROC MIXED in SAS. The assumptions of the models were checked. Colony variable had heterogeneous variances, and the variance grouping technique was

TABLE 1. Effects of UV-C ( $254 \mathrm{~nm})$ exposure followed by a dark incubation period on viability of Botrytis cinerea conidia tested on potato dextrose agar (PDA) 24 and $48 \mathrm{~h}$ after the treatment

\begin{tabular}{|c|c|c|c|c|c|c|}
\hline \multicolumn{7}{|c|}{ Number of colonies developed on PDA } \\
\hline \multirow{3}{*}{$\begin{array}{l}\text { Incubation } \\
\text { in dark (h) }\end{array}$} & \multicolumn{3}{|c|}{$24 \mathrm{~h}$} & \multicolumn{3}{|c|}{$48 \mathrm{~h}$} \\
\hline & \multicolumn{3}{|c|}{$\begin{array}{c}\text { UV-C } \\
\text { exposure (s) }\end{array}$} & \multicolumn{3}{|c|}{$\begin{array}{c}\text { UV-C } \\
\text { exposure (s) }\end{array}$} \\
\hline & 0 & 30 & 60 & 0 & 30 & 60 \\
\hline 0 & 0 & 0 & 0 & $34.67 \mathrm{aA}^{\mathrm{z}}$ & $20.67 \mathrm{abB}$ & $12.67 \mathrm{aB}$ \\
\hline 1 & 0 & 0 & 0 & $22.33 \mathrm{bA}$ & $20.00 \mathrm{aA}$ & $5.00 \mathrm{abB}$ \\
\hline 2 & 0 & 0 & 0 & $22.00 \mathrm{bcA}$ & $18.33 \mathrm{abcA}$ & $3.33 \mathrm{bB}$ \\
\hline 3 & 0 & 0 & 0 & $23.67 \mathrm{bA}$ & $15.67 \mathrm{abcB}$ & $0.67 \mathrm{bC}$ \\
\hline 4 & 0 & 0 & 0 & $19.67 \mathrm{bcA}$ & $13.00 \mathrm{bcA}$ & $0.17 \mathrm{bC}$ \\
\hline 5 & 0 & 0 & 0 & $13.00 \mathrm{cB}$ & $27.67 \mathrm{aA}$ & $0.17 \mathrm{bC}$ \\
\hline 6 & 0 & 0 & 0 & $21.00 \mathrm{bcA}$ & $11.33 \mathrm{cB}$ & $0.17 \mathrm{bC}$ \\
\hline
\end{tabular}

$\mathrm{z}$ Values followed by the same lowercase letter in the same column are not significantly different according to Sidak adjusted $P$ values so that the experiment-wise error was 0.05 . Values followed by the same uppercase letter in the same row are not significantly different according to Sidak adjusted $P$ values so that the experiment-wise error was 0.05 . used to correct the variance heterogeneity. Mean comparisons were done with Sidak adjusted $P$ values so that the experiment-wise error was 0.05 .

The effect of UV-C on pollen germination was analyzed using the Jonckheere-Terpstra exact $\chi^{2}$ goodness test (StatXact, Cytel Software Corp.) for a doubly ordered frequency table to determine if the pollen germination was the same for 0 and $60 \mathrm{~s} \mathrm{UV-C}$ treatment across the germination ratings.

The effect of UV-C treatments on pollen tube length was analyzed for equivalence using PROC TTEST in SAS. The equality of variances was checked and the Satterthwaite adjusted equivalence test was used.

To determine the effect of UV-C treatments on incidence of gray mold on strawberry fruit, the exact Kruskal-Wallis (StatXact) was used. If the overall $\chi^{2}$ was statistically significant, then the means were compared using Sidak adjusted $P$ value so that the experiment error rate was 0.05 .

The effects of UV-C treatments on fruit weight variables were analyzed as a one-factor linear model with UV-C treatment as the factor using PROC MIXED in SAS. The assumptions of the models were checked. One value was a potential outlier (Fungicide Rep 2) and the analysis was done with and without the value. For total count there was some indication of variance heterogeneity when using all the observations in the analysis so the variance grouping technique was used in that case. This was not needed when the outlier was omitted from the analysis. Mean comparisons were done with Sidak adjusted $P$ values so that the experiment-wise error was 0.05 .

\section{RESULTS}

Effect of incubation in the dark on sensitivity of $B$. cinerea conidia to UV-C treatment. No visible $B$. cinerea colonies were observed on PDA plates after $24 \mathrm{~h}$ incubation, and after $48 \mathrm{~h}$ small, distinct colonies appeared on PDA. Irradiation of the $B$. cinerea conidia with UV-C for $60 \mathrm{~s}$ significantly $(P=0.05)$ reduced conidia viability and subsequent colony development from 35 to 13 colonies/plate when conidia were exposed to continuous incandescent light immediately following irradiation (Table 1). However, when irradiated conidia from the same experimental batch were subjected to a dark period immediately after irradiation before exposure to continuous incandescent light, germination and development of the colonies were reduced further as the dark period increased up to $2 \mathrm{~h}$ (Table 1 ). At this point only a few colonies developed on plates subjected to longer dark periods and on a majority of plates no colonies developed at all. Although colony counts on nonirradiated plates kept in continuous light were significantly higher than those kept in the dark, the differences among counts in various dark periods varied slightly and on the plates incubated for $96 \mathrm{~h}$ no visible differences in fungal growth were observed among all nonirradiated treatments (Supplementary Fig. S2).

Effect of UV-C on pollen viability. Irradiation of strawberry pollen with UV-C for 60 s had no negative effect $(P=0.05)$ on pollen viability as determined by fluorescent staining with $\mathrm{H}_{2}$ DCF-DA and concurrent count using bright field illumination. The viability was greater than $80 \%$ for the nonirradiated and more than $90 \%$ for irradiated pollen (Table 2).

Effect of UV-C on pollen germination and germ tube length. Irradiation of strawberry pollen with UV-C for $60 \mathrm{~s}$ followed by a 4-h dark period had no negative effect on pollen

TABLE 2. Effect of UV-C ( $254 \mathrm{~nm})$ exposure followed by a 4-h dark period on strawberry pollen viability

\begin{tabular}{lccc}
\hline & \multicolumn{2}{c}{ Pollen count } & \\
\cline { 2 - 3 } UV-C exposure (s) & Viable & Total & Viability $(\%)^{\mathrm{z}}$ \\
\hline 0 & 254 & 314 & 80.9 \\
60 & 295 & 311 & 94.9 \\
\hline
\end{tabular}

There were no statistical differences between means of viability (\%) according to a $t$ test $(P=0.05)$. 
germination $\left(\chi^{2}=1.94, P=0.0628\right)$. Different stages of the pollen germination also appeared not to be affected by exposure to the UV-C treatment (Table 3). Also, irradiation of strawberry pollen with UV-C for $60 \mathrm{~s}$ followed by a 4-h dark period had no negative effect

TABLE 3. Effect of UV-C (254 nm) exposure followed by a 4-h dark period on germination of strawberry pollen incubated in sucrose/boric acid medium overnight $(\sim 16 \mathrm{~h})$ at $25^{\circ} \mathrm{C}$

\begin{tabular}{lccccc}
\hline & \multicolumn{4}{c}{ Rating $^{\mathrm{y}}$} \\
\cline { 2 - 5 } UV-C exposure (s) & 1 & 2 & 3 & 4 & Germination $(\%)^{\mathrm{z}}$ \\
\hline 0 & 37 & 12 & 25 & 226 & 86.0 \\
60 & 22 & 16 & 17 & 245 & 92.7 \\
\hline
\end{tabular}

${ }^{y}$ Rating: $1=$ not germinated, $2=$ pollen tube length $<2 \times$ pollen diameter, $3=$ pollen tube length $2 \times$ to $4 \times$ pollen diameter, and $4=$ pollen tube length $\geq 4 \times$ pollen diameter.

$\mathrm{z}$ The pollen germination rate across the ratings was not significantly different $\left(\chi^{2}=1.94, P=0.0628, \mathrm{df}=1\right)$.

TABLE 4. Average length of strawberry pollen tube after UV-C (254 nm) irradiation followed by a 4-h dark period and incubation in sucrose/boric acid medium overnight at $25^{\circ} \mathrm{C}$

\begin{tabular}{llc}
\hline UV-C exposure $(\mathrm{s})$ & \multicolumn{2}{l}{ Pollen tube length $(\mu \mathrm{m})$} \\
\hline 0 & 187.2 & $( \pm 25.8)^{\mathrm{z}}$ \\
60 & 178.2 & $( \pm 12.8)$ \\
\hline
\end{tabular}

z Standard error of the measurement of 100 pollen tubes for each of three replicates. There were no statistical differences between means according to a $t$ test $(P=0.05)$.
$(P=0.05)$ on average pollen tube length in sucrose/boric acid medium (Table 4, Fig. 1A and B).

Effect of UV-C on flower pollination. Pollination of emasculated strawberry flowers with pollen irradiated for $60 \mathrm{~s}$ and kept in the dark for $4 \mathrm{~h}$ resulted in massive germination on the stigma and rapid tube growth through the style to the ovary (Fig. 1C and D).

Effect of UV-C on photosynthesis. No change in photosynthesis occurred in leaves of strawberry plants irradiated with UV-C for 30 or $60 \mathrm{~s}$ twice a week for 7 weeks (Supplementary Fig. S3). However, significant chlorophyll damage was observed on plants that had been irradiated a single time for an extended exposure of 2,4 , or $6 \mathrm{~h}$, and the damage visibly increased with incubation time until day 11, the duration of the experiment (Supplementary Fig. S4).

Effect of UV-C on dry conidia viability and infectivity. Irradiation of dry conidia for $60 \mathrm{~s}$ followed by a 4-h dark period reduced the viability of $B$. cinerea conidia from 89 to 20 colonies per plate $(77.5 \%$ reduction) (Table 5$)$. Although, some conidia were still viable they were not able to cause infection in apple wounds inoculated with $25 \mu \mathrm{l}$ of $10^{4}$ conidia/ml (250 irradiated conidia per wound).

Control of fruit decay on inoculated strawberries. Treatment of wounded strawberry fruit inoculated with $B$. cinerea conidia that had been irradiated with UV-C for $60 \mathrm{~s}$ followed by a 4-h dark period significantly $(P=0.05)$ reduced decay on the fruit after 3,5 , and 7 days ( 3 days: $\chi^{2}=15.43, P=0.02213, \mathrm{df}=5 ; 5$ days: $\chi^{2}=36.52$, $P=0.0001$, df $=5$; and 7 days: $\chi^{2}=52.67, P=0.0001$, df $=5$ ) incubation (Table 6, Fig. 2). After 7 days the amount of decay was

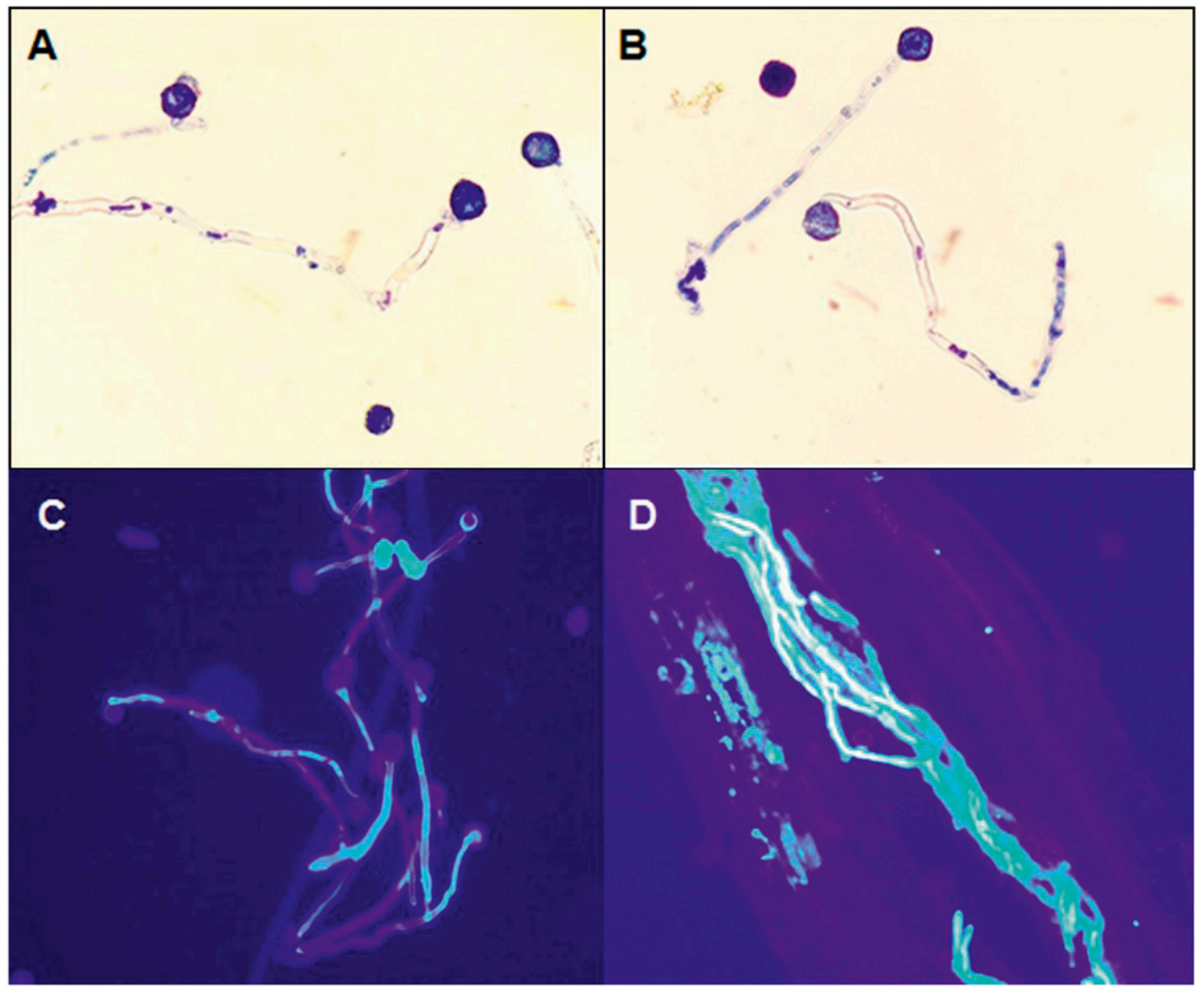

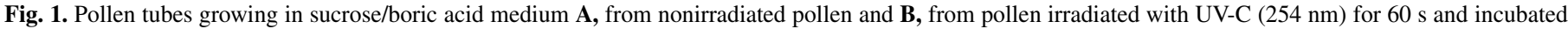

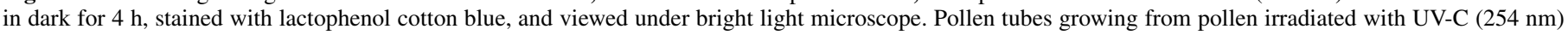

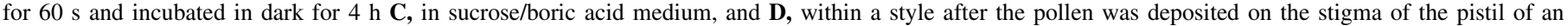
emasculated strawberry flower, stained with aniline blue, and viewed under fluorescent microscope. 
reduced by $50 \%$. Increasing UV-C doses to 90 and 120 s completely eliminated decay without any negative effect on the appearance of the sepals (Table 6).

Control of strawberry petal infection. Petal infection was significantly $(P=0.05)$ reduced by $60 \mathrm{~s} \mathrm{UV-C} \mathrm{treatment} \mathrm{followed} \mathrm{by}$

TABLE 5. Viability and infectivity of Botrytis cinerea conidia after UV-C $(254 \mathrm{~nm})$ exposure of dry conidia and a 4-h dark period before plating and fruit inoculation

\begin{tabular}{lccc}
\hline UV-C exposure & $\begin{array}{c}\text { Colony count } \\
\text { per plate }\end{array}$ & $\begin{array}{c}\text { Reduction in } \\
\text { viability }(\%)\end{array}$ & $\begin{array}{c}\text { Infection of } \\
\text { apple wounds }^{z}\end{array}$ \\
\hline $0 \mathrm{~s}$ & 89 & - & + \\
$60 \mathrm{~s}$ & 20 & 77.5 & - \\
$2 \mathrm{~min}$ & 18 & 79.8 & - \\
$4 \mathrm{~min}$ & 5 & 94.4 & - \\
\hline
\end{tabular}

${ }^{\mathrm{z}}$ Each wound was inoculated with $25 \mu \mathrm{l}$ of $10^{4}$ conidia/ml suspension.

TABLE 6. Incidence of gray mold on strawberry fruit that were wounded and inoculated with either sterile tap water (STW) or suspension of Botrytis cinerea and irradiated with UV-C ( $254 \mathrm{~nm})$ for various times followed by a 4-h dark incubation

\begin{tabular}{|c|c|c|c|}
\hline \multirow[b]{2}{*}{ Treatment } & \multicolumn{3}{|c|}{ Incidence of gray mold (\%) } \\
\hline & 3 days & 5 days & 7 days \\
\hline STW & $0.0 \mathrm{~b}^{\mathrm{y}}$ & $0.0 \mathrm{~b}$ & $0.0 \mathrm{~b}$ \\
\hline $\mathrm{STW}+60 \mathrm{~s}$ UV-C & $0.0 \mathrm{~b}$ & $0.0 \mathrm{~b}$ & $0.0 \mathrm{~b}$ \\
\hline B. cinerea & $25.0 \mathrm{a}( \pm 16.0)^{\mathrm{z}}$ & $75.0 \mathrm{a}( \pm 8.3)$ & $100.0 \mathrm{a}$ \\
\hline $\begin{array}{l}\text { B. cinerea }+60 \mathrm{~s} \\
\mathrm{UV}-\mathrm{C}\end{array}$ & $0.0 \mathrm{~b}$ & $41.7 \mathrm{ab}( \pm 16.0)$ & $50.0 \mathrm{ab}( \pm 9.6)$ \\
\hline $\begin{array}{l}\text { B. cinerea }+90 \mathrm{~s} \\
\mathrm{UV}-\mathrm{C}\end{array}$ & $0.0 \mathrm{~b}$ & $0.0 \mathrm{~b}$ & $0.0 \mathrm{~b}$ \\
\hline $\begin{array}{l}\text { B. } \text { cinerea }+120 \mathrm{~s} \\
\mathrm{UV}-\mathrm{C}\end{array}$ & $0.0 \mathrm{~b}$ & $0.0 \mathrm{~b}$ & $0.0 \mathrm{~b}$ \\
\hline
\end{tabular}

y Values followed by the same letter in the same column are not significantly different according to Sidak adjusted $P$ values so that the experiment-wise error was 0.05 .

${ }^{\mathrm{z}}$ Standard error of the mean of four replicates. a dark period of $4 \mathrm{~h}$ on petals incubated for 5 days, when more petals were infected and the lesions were clearly visible (Table 7). The differences in petal infection between the UV-C-treated and the control were not statistically different after incubation for 3 days; however, the tendency toward lower infection on UV-C-treated petals was clearly visible.

Fruit yield of UV-C-treated strawberry plants in a preliminary high tunnel test. Irradiation treatment of strawberry plants twice a week for eight consecutive weeks did not have significant $(P=$ $0.05)$ negative effect on production of healthy fruit per plant, and number of deformed and total fruit in high tunnel culture (Table 8). The weight of the well-shaped and deformed fruit was also not affected.

\section{DISCUSSION}

Incubating $B$. cinerea conidia in the dark immediately after UV-C exposure on agar plates resulted in a drastic increase in kill of conidia over those incubated in continuous light. At $60 \mathrm{~s}$ irradiation at $206 \mu \mathrm{W} / \mathrm{m}^{2}$, resulting in $0.001236 \mathrm{~J} / \mathrm{cm}^{2}$, no colonies developed on most agar plates kept in the dark for $4 \mathrm{~h}$ after irradiation. This effect is more drastic than that reported for B. fabae where after $60 \mathrm{~s}$ of UV-C exposure at an intensity of $173 \mu \mathrm{W} / \mathrm{m}^{2}$ and a dark period of $7 \mathrm{~h}$, almost one third of the conidia produced lesions on bean leaves (Buxton et al. 1957). There are indications that powdery mildew of strawberry, caused by Podosphaera aphanis, and anthracnose, caused by Colletotrichum acutatum, could also be controlled with the UV-C treatment regime developed for control of $B$. cinerea (Janisiewicz et al. 2015). The mycelium of $P$. aphanis resides mainly on plant surfaces and, as in another example with powdery mildew fungus on beans (Erysiphe graminis), it is vulnerable to UV-C treatment (Buxton et al. 1957). Work with UV-B treatment on roses also indicates high susceptibility of powdery mildew; however, with this wavelength, treatments of $5 \mathrm{~min}$ to $1 \mathrm{~h}$ were needed to achieve any significant effect (Suthaparan et al. 2012).

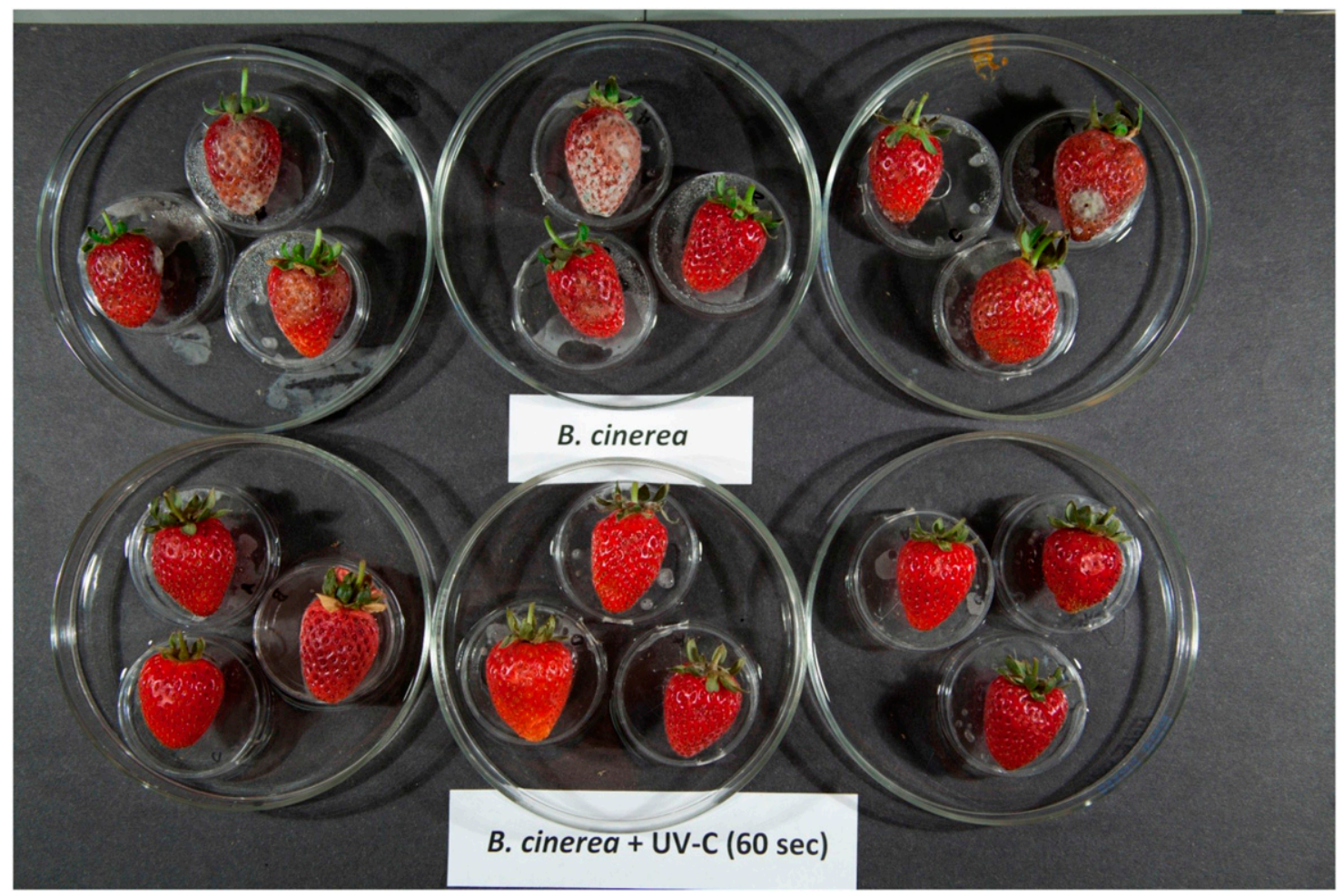

Fig. 2. Example of control of fruit decay on wounded fruit inoculated with Botrytis cinerea using UV-C irradiation for $60 \mathrm{~s}$ followed by $4 \mathrm{~h}$ of dark period and incubation for 5 days at $22^{\circ} \mathrm{C}$. 
Lammertyn et al. (2003) observed sepal dehydration and subsequent browning on harvested strawberries irradiated with doses higher than $0.1 \mathrm{~J} / \mathrm{cm}^{2}$, a dose that did not provide adequate control. To improve control they combined UV-C irradiation with heat treatment and white light pulses (Marquenie et al. 2002a, 2003); however, the results still were not satisfactory. Relying solely on treatment(s) after harvest for controlling strawberry decay may be only partially effective as most of the infections resulting in fruit decay originate in the field during bloom (Bulgler et al. 1987; Mertely et al. 2002). Thus, the control treatments will have to be applied as early as the onset of bloom and continue until harvest. In addition, considering the UV-C damage to sepals, it has been important to determine if the UV-C treatment required for killing $B$. cinerea had any negative effect on the photosynthetic apparatus, which in turn may affect not only plant growth and fruit yield, but also the appearance of strawberry fruit, particularly the sepals.

Maintaining a dark environment after exposure to a damaging UV-C irradiation can prevent light activation of the DNA repair mechanism in microorganisms (Beggs 2002; Beggs et al. 2006; Essen and Klar 2006) and, most likely, this mechanism contributed to the reduction of the UV-C dose required to kill $B$. cinerea to $0.001236 \mathrm{~J} / \mathrm{cm}^{2}$, which is below the levels resulting in damage to the sepals reported by Lammertyn et al. (2003). Even after exposing strawberry plants to this dose twice a week for 7 weeks we did not observe any reduction in photosynthesis in leaves as determined by Maximal PS II Quantum Yield at chlorophyll resting stage nor any obvious damage to sepals (sound fruit). We also did not observe any negative effect of this UV-C dose on pollen germination, tube growth, and length of the tube in vitro and in situ. The lack of the negative effects indicates the potential usefulness of this UV-C approach in controlling diseases of strawberries. Although irradiation of dry conidia of $B$. cinerea at this dose $\left(0.001236 \mathrm{~J} / \mathrm{cm}^{2}\right)$ resulted in survival of some conidia, they were not able to cause infections on wounded apple fruit. The observed loss of infectivity prior to loss of viability of $B$. cinerea conidia after UV-C irradiation is in agreement with earlier reports with other plant pathogens (Buxton et al. 1957; Moseman and Greeley 1966).

The great reduction of strawberry petal infection by the UV-C treatment on artificially inoculated petals suggests that this approach could be very effective in reducing a large portion of fruit infections as the majority of strawberry fruit decays

TABLE 7. Incidence of gray mold on detached strawberry flower petals that were inoculated with a suspension of Botrytis cinerea conidia and irradiated with UV-C $(254 \mathrm{~nm})$ for $60 \mathrm{~s}$ followed by a 4-h dark incubation

\begin{tabular}{|c|c|c|c|c|}
\hline \multirow{3}{*}{$\frac{\text { Treatment }}{\text { B. cinerea }}$} & \multicolumn{4}{|c|}{ Incidence of infection $(\%)$} \\
\hline & \multicolumn{2}{|c|}{3 days } & \multicolumn{2}{|c|}{5 days } \\
\hline & $50.0 \mathrm{a}^{\mathrm{y}}$ & $( \pm 16.0)^{\mathrm{z}}$ & $75.0 \mathrm{a}$ & $( \pm 8.3)$ \\
\hline B. cinerea $+60 \mathrm{~s} \mathrm{UV}-\mathrm{C}$ & $16.7 \mathrm{a}$ & $( \pm 0.0)$ & $33.3 \mathrm{~b}$ & $( \pm 16.0)$ \\
\hline
\end{tabular}

y Means with the same letter in the same column are not significantly different according to a $t$ test $(P=0.05)$.

${ }^{\mathrm{z}}$ Standard error of the mean of four replicates. originate from flower infection. In addition, results from the UV-C treatment of artificially inoculated wounded strawberry fruit indicate that this treatment can be effective also under very severe conditions present at the wound site of a mature fruit. Since our preliminary test in the high tunnel indicates no negative effect of the UV-C on fruit set, quality and yield, this treatment may be useful in commercial production. The disease pressure in this preliminary test was purposefully maintained at a very low level; however, future pilot tests using this technology should include cultivars with varying susceptibility to the disease and an application of the pathogen inoculum to increase disease pressure in order to demonstrate levels of effectiveness of the UV-C treatment under various conditions. Duration, intensity, and frequency of the UV-C irradiation should also be included in such tests to optimize the treatment (Van Delm et al. 2014).

Fungicide residue on harvested fruit is a big concern to consumers and self-imposed restrictions on their residue by supermarket chains in various countries may create additional barriers for exporting fruit to those countries (Vorstermans and Creemers 2011). UV-C treatment of plants to control diseases is a very attractive alternative to synthetic fungicides because it does not leave any residue and does not requires a reentry period after application, which can be a significant problem, e.g., during harvesting, especially in closed environment cultures. The UV-C treatment may also induce resistance in plants, which may, indirectly, improve control of various pre- and postharvest pathogens (Nigro et al. 1998, 2000; Petit et al. 2009; Pombo et al. 2011; Wilson et al. 1994). Adding the dark incubation period reduces the amount of energy that must be used to kill pathogens making this approach more cost effective. In addition, this treatment is compatible with organic production and indoor vertical production in urban areas where the use of synthetic fungicides is severely restricted and/or not allowed.

Irradiation of strawberry plants with UV-C can kill, in addition to the pathogens, a significant part of the microbial population on the plant surface, creating a microbial "vacuum." This will result in a lack of competition from the natural microbial populations to newly arriving airborne conidia of a pathogen giving it an ecological advantage to colonize the plant. Results from limited studies indicate that after an initial decline, microbial populations recover rather quickly and even increase beyond the original levels, presumably because of the release of nutrients from plant cells during UV-C irradiation (Nigro et al. 1998; Paul et al. 2012; Sztejnberg and Blakeman 1973). However, the population recoveries may not be rapid enough to prevent development of iatrogenic diseases (Griffiths 1981) and composition of the recovered microflora may or may not be favorable to the pathogen, exposing the system to considerable potential variation. Thus, in order to reduce this variation we envision the application of biocontrol agents that can efficiently colonize plant parts most vulnerable to infection by $B$. cinerea, such as flowers and fruit, immediately after UV-C treatment. This may also provide opportunities to optimize the effectiveness of biocontrol, and thus enhance overall disease control. Both UV-C and biocontrol treatments with antagonists are acceptable organic treatments, which are very much needed for the rapidly expanding organic market.

TABLE 8. Yield and quality of strawberry fruit harvested over 5-week period from 'Albion' plants irradiated with UV-C twice a week in 2013 high tunnel test

\begin{tabular}{lccccccc}
\hline & \multicolumn{3}{c}{ Fruit weight $(\mathrm{g})$} & & \multicolumn{2}{c}{ Fruit count } \\
\cline { 2 - 4 } Treatment & Healthy & Well-shaped & Deformed & & Total & Deformed & Healthy fruit per plant (g) \\
\hline No UV-C & $1,458.7 \mathrm{a}^{\mathrm{y}}$ & $1,299.0 \mathrm{ab}$ & $198.7 \mathrm{a}$ & & $78.6 \mathrm{ab}$ & $15.2 \mathrm{a}$ & $364.7 \mathrm{a}$ \\
UV-C 30 s & $1,371.7 \mathrm{a}$ & $1,211.8 \mathrm{ab}$ & $152.4 \mathrm{a}$ & & $67.4 \mathrm{~b}$ & $10.8 \mathrm{a}$ & $342.9 \mathrm{a}$ \\
UV-C 60 s & $1,543.5 \mathrm{a}$ & $1,423.3 \mathrm{a}$ & $133.6 \mathrm{a}$ & & $84.6 \mathrm{a}$ & $11.2 \mathrm{a}$ & $385.9 \mathrm{a}$ \\
Fungicide $^{\mathrm{z}}$ & $1,211.5 \mathrm{a}$ & $1,041.4 \mathrm{~b}$ & $173.6 \mathrm{a}$ & & $65.0 \mathrm{ab}$ & $11.8 \mathrm{a}$ & $302.9 \mathrm{a}$ \\
\hline
\end{tabular}

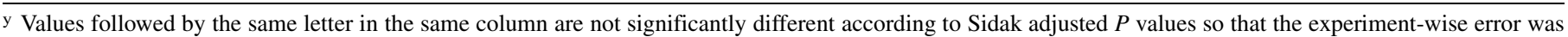
0.05 .

z Pyraclostrobin, boscalid and pyraclostrobin, and fenhexamid in rotation. 


\section{ACKNOWLEDGMENTS}

We thank S. Yarrington and B. Nichols for excellent technical assistance in conducting UV-C experiments, S. Wolford for his invaluable skills in making a dependable UV-C irradiation apparatus, and N. Snyder for maintaining strawberry plants. Mention of trade names or commercial products in this publication is solely for the purpose of providing specific information and does not imply recommendation or endorsement by the USDA. USDA is an equal opportunity provider and employer. This research was supported by USDA CRIS 8080-22000-009-00D.

\section{LITERATURE CITED}

Adrian, M., Jeandet, P., Douillet-Breuil, A. C., Tesson, L., and Bessis, R. 2000. Stilbene content of mature Vitis vinifera berries in response to UV-C elicitation. J. Agric. Food Chem. 48:6103-6105.

Allende, A., McEvoy, J. L., Luo, Y., Artes, F., and Wang, C. Y. 2006. Effectiveness of two-sided UV-C treatments in inhibiting natural microflora and extending the shelf-life of minimally processed 'Red Oak Leaf' lettuce. Food Microbiol. 23:241-249.

Bachmann, R. 1975. Sterilization by intensive ultraviolet radiation. Brown Boveri Rev. 62:206-209.

Beggs, C. B. 2002. A quantitative method for evaluating the photoreactivation of ultraviolet damaged microorganism. Photochem. Photobiol. Sci. 1:431-437.

Beggs, C. B., Noakes, C. J., Sleigh, P. A., Fletcher, L. A., and Kerr, K. G. 2006. Methodology for determining the susceptibility of airborne microorganisms to irradiation by an upper-room UVGI system. Aerosol Sci. 37:885-902.

Bhatt, D. D., and Vaughan, E. K. 1962. Preliminary investigation on biological control of gray mold (Botrytis cinerea) on strawberries. Plant Dis. Rep. 46: 342-345.

Bintsis, T., Litopoulou-Tzanetaki, E., and Robinsos, R. K. 2000. Existing and potential applications of ultraviolet light in the food industry-A critical review. J. Sci. Food Agric. 80:637-645.

Bulger, M. A., Ellis, M. A., and Madden, L. V. 1987. Influence of temperature and wetness duration on infection of strawberry flowers by Botrytis cinerea and disease incidence of fruit originating from infected flowers. Phytopathology 77:1225-1230.

Burlakoti, R. R., Zandstra, J., and Jackson, K. 2013. Comparison of epidemiology of gray mould, anthracnose fruit rot, and powdery mildew in dayneutral strawberries in field and high-tunnel conditions in Ontario. Int. J. Fruit Sci. 13:19-27.

Buxton, E. W., Last, F. T., and Nour, M. A. 1957. Some effects of ultraviolet radiation on the pathogenicity of Botrytis fabe, Uromyces fabe and Erysiphe graminis. J. Gen. Microbiol. 16:764-773.

Carisse, O., Lefebvre, A., Van der Hayden, H., Roberge, L., and Brodeur, L. 2013. Analysis of incidence-severity relationship for strawberry powdery mildew as influenced by cultivar, cultivar type, and production system. Plant Dis. 97:354-362.

Chalutz, E., Droby, S., Wilson, C., and Wisniewski, M. 1992. UV-induced resistance to postharvest diseases of citrus fruit. J. Phytochem. Phytobiol. $15: 367-374$.

Charles, M. T., Arul, J., and Gosselin, C. 1999. Induction of resistance to gray mold and accumulation of the phytoalexin rishitin in tomato fruits by UV-C. (Abstr.) Phytopathology 89(Suppl.):S14.

Droby, S., Chalutz, E., Horev, B., Cohen, L., Gaba, V., Wilson, C. L., and Wisniewski, M. E. 1993. Factors affecting UV-induced resistance in grapefruit against the green mould decay caused by Penicillium digitatum. Plant Pathol. 42:418-424.

Escalona, V. H., Aguayo, E., Martínez-Hernández, G. B., and Artés, F. 2010. UV-C doses to reduce pathogen and spoilage bacterial growth in vitro and in baby spinach. Postharvest Biol. Technol. 56:223-231.

Essen, L. O., and Klar, T. 2006. Review: Light-driven DNA repair by photolyases. Cell. Mol. Life Sci. 63:1266-1277.

Gardner, D. W., and Shama, G. 2000. Modeling UV-induced inactivation of microorganisms on surfaces. J. Food Prot. 63:63-73.

Graça, A., Salazar, M., Quintas, C., and Nunes, C. 2013. Low dose UV-C illumination as an eco-innovative disinfection system on minimally processed apples. Postharvest Biol. Technol. 85:1-7.

Griffiths, E. 1981. Iatrogenic plant diseases. Annu. Rev. Phytopathol. 19: 69-82.

Hanson, E. J., Gluck, B. I., and Schilder, A. 2013. High tunnels for organic raspberry production in the Midwestern US. Int. J. Fruit Sci. 13:73-77.

Hijnen, W. A., Beerendonk, E. F., and Medema, G. J. 2006. Inactivation credit of UV radiation for viruses, bacteria and protozoan oocyst in water: A review. Water Res. 40:3-22.

Janisiewicz, W. J., and Conway, W. S. 2011. Combining biological control with physical and chemical treatments to control fruit decays after harvest. Stewart Postharvest Rev. 9:1-16.
Janisiewicz, W. J., Takeda, F., Jurick W., II, Nichols, B., Wolford, S., and Glenn, D. M. 2015. A novel approach to control gray mold, anthracnose, and powdery mildew on strawberry using low-dose UV-C irradiation. (Abstr.) Phytopathology 105(Suppl.):S4.64.

Karabulut, O. A., Tezcan, H., Daus, A., Cohen, L., Wiess, B., and Droby, S. 2004. Control of preharvest and postharvest fruit rot in strawberry by Metschnikowia fructicola. Biocontrol Sci. Technol. 14:513-521.

Lammertyn, J., De Ketelaere, B., Marquenie, D., Molenberghs, G., and Niocolai, B. M. 2003. Mixed models for multicategorical repeated response: Modeling the time effect of physical treatments on strawberry sepal quality. Postharvest Biol. Technol. 30:195-207.

Last, F. T., and Buxton, E. W. 1955. Photo-reactivation of Botrytis fabe Sardiňa measured by a local-lesion technique. Nat. Lond. 176:655.

Lima, G., Ippolito, A., Nigro, F., and Salerno, M. 1997. Effectiveness of Aureobasidium pullulans and Candida oleophila against postharvest strawberry rots. Postharvest Biol. Technol. 10:169-178.

Marquenie, D., Lammertyn, J., Geeraerd, A. H., Soontjens, C., Van Impe, J. F., Nicolai, B. M., and Michiels, C. W. 2002b. Inactivation of conidia of Botrytis cinerea and Monilinia fructigena using UV-C and heat treatment. Int. J. Food Microbiol. 74:27-35.

Marquenie, D., Michiels, C. W., Geeraerd, A. H., Schenk, A., Soontjens, C., Van Impe, J. F., and Nicolai, B. M. 2002a. Using survival analysis to investigate the effect of UV-C and heat treatment on storage rot of strawberry and sweet cherry. Int. J. Food Microbiol. 73:187-196.

Marquenie, D., Michiels, C. W., Van Impe, J. F., Schrevens, E., and Nicolaï, B. N. 2003. Pulsed white light in combination with UVC and heat to reduce storage rot of strawberry. Postharvest Biol. Technol. 28:455-461.

Mercier, J., Roussel, D., Charles, M.-T., and Arul, J. 2000. Systemic and local responses associated with UV- and pathogen-induced resistance to Botrytis cinerea in stored carrots. Phytopathology 90:981-986.

Mertely, J. C., MacKenzie, S. J., and Legard, D. E. 2002. Timing of fungicide application for Botrytis cinerea based on development stage of strawberry flowers and fruit. Plant Dis. 86:1019-1024.

Moseman, J. G., and Greeley, L. W. 1966. Effect of ultraviolet light on Erysiphe graminis f. sp. hordei. Phytopathology 56:1357-1360.

Moser, R., Pertot, I., Elad, Y., and Raffaelli, R. 2008. Farmers' attitudes toward the use of biocontrol agents in IPM strawberry production in three countries. BioControl 47:125-132.

Nigro, F., Ippolito, A., Lattanzio, V., Di Venere, D., and Salerno, M. 2000. Effect of ultraviolet-C light on postharvest decay of strawberry. J. Plant Pathol. 82:29-37.

Nigro, F., Ippolito, A., and Lima, G. 1998. Use of UV-C light to reduce Botrytis storage rot of table grapes. Postharvest Biol. Technol. 13:171-181.

Offner, J. 2013. Organic category mostly oblivious to economic swings. The Packer. http://www.thepacker.com/fruit-vegetable-news/marketing-profiles/ organic/Category-mostly-oblivious-to-economic-swings-186517471.html

Paul, D. N., More, J. P., McPherson, M., Lambourne, C., Croft, P., Heaton, J., and Wargent, J. J. 2012. Ecological responses to UV radiation: interaction between the biological effects of UV on plants and on associated organisms. Physiol. Plant. 145:565-581.

Peng, G., Sutton, J. C., and Kevan, P. G. 1992. Effectiveness of honey bees for applying the biocontrol agent Gliocladium roseum to strawberry flowers to suppress Botrytis cinerea. Can. J. Plant Pathol. 14:117-129.

Pertot, I., Zasso, R., Amsalem, L., Baldessari, M., Angeli, G., and Elad, Y. 2008. Integrating biocontrol agents in strawberry powdery mildew control strategies in high tunnel growing system. Crop Prot. 27:622-631.

Petit, A.-N., Baillieul, F., Vaillant-Gaveau, N., Jacquens, L., Conreux, A., Jeandet, P., Clément, C., and Fontaine, F. 2009. Low responsiveness of grapevine flowers and berries at fruit set to UV-C irradiation. J. Exp. Bot. 60:1155-1162.

Picket-Pottorff, L., and Panter, K. L. 2009. Integrated pest management and biological control in high tunnel production. HortTechnol. 19:61-65.

Pombo, M. P., Rosli, H. G., Martinez, G. A., and Civello, P. M. 2011. UV-C treatment affects the expression and activity of defense genes in strawberry fruit (Fragaria $\times$ ananassa, Duch.). Postharvest Biol. Technol. 59:94-102.

Schenk, M., García Loredo, A., Raffellini, S., Alzamora, S. M., and Guerrero, S. 2012. The effect of UV-C in combination with $\mathrm{H}_{2} \mathrm{O}_{2}$ treatments on microbial response and quality parameters of fresh cut pear discs. Int. J. Food Sci. Technol. 47:1842-1851.

Shaw, D. V., and Larson, K. D. 2006. Strawberry plant named 'Albion'. U.S. Plant Patent No. PP16228.

Shaw, D. V., and Larson, K. D. 2009. Strawberry plant named 'Monterey'. U.S. Plant Patent No. PP19767.

Smith, B. J. 2013. Strawberry anthracnose: Progress toward control through science. Int. J. Fruit Sci. 13:91-102.

Stevens, C., Khan, V. A., Lu, J. Y., Wilson, C. L., Pusey, P. L., Kabwe, M. K., Igwegbe, E. C. K., Chalutz, E., and Droby, S. 1998. The germicidal and hormetic effects of UV-C light on reducing brown rot disease and yeast microflora of peaches. Crop Prot. 17:75-84. 
Stevens, C., Khan, V. A., Tang, A. Y, and Lu, J. Y. 1990. The effect of ultraviolet radiation on mold rots and nutrients of stored sweet potatoes. J. Food Prot. 53:223-226.

Suthaparan, A., Stensvand, A., Solhaug, K. A., Torre, S., Mortensen, L. M., Gadoury, D. M., Seem, R. C., and Gislerød, H. R. 2012. Suppression of powdery mildew (Podosphaera pannosa) in greenhouse roses by brief exposure to supplemental UV-B radiation. Plant Dis. 96:1653-1660.

Sylla, J., Alsanius, B. W., Kruger, E., Becker, D., and Wohanka, W. 2013. In vitro compatibility of microbial agents for simultaneous application to control strawberry powdery mildew (Podosphaera aphanis). Crop Prot. 51: 40-47.

Sztejnberg, A., and Blakeman, J. P. 1973. Ultraviolet-induced changes in populations of epiphytic bacteria on beetroot leaves and their effect on germination of Botrytis cinerea spores. Physiol. Plant Pathol. 3:443-451.

Van Delm, T., Melis, P., Stoffels, K., and Beats, W. 2014. Control of powdery mildew by UV-c treatment in commercial strawberry production. Pages 679-684 in: Proc. 7th Intl. Strawberry Symp. Y. Zhang and J. Maas, eds. ISHS. Acta Hort. 1049.
Vorstermans, B., and Creemers, P. 2011. Current status of development of biological control products for postharvest use in Europe. Acta Hortic. 905:313-318.

Wedge, D. E., Quebedeaux, J. P., Constantine, R. J., and Smyth, B. J. 2007. Fungicide management strategies for control of strawberry fruit rot diseases in Louisiana and Mississippi. Crop Prot. 26:1449-1458.

Wilcox, W. F., and Seem, R. C. 1994. Relationship between strawberry gray mold incidence, environmental variables, and fungicide application during different periods of the fruiting season. Phytopathology 84:264-270.

Wilson, C. L., El Ghaouth, A., Chalutz, E., Droby, S., Stevens, C., Lu, J. Y., Khan, V., and Arul, J. 1994. Potential of induced resistance to control postharvest diseases of fruits and vegetables. Plant Dis. 78:837-844.

Xiao, C. L., Chandler, C. K., Price, J. R., Duval, J. R., Mertely, J. C., and Legard, D. E. 2001. Comparison of epidemics of Botrytis fruit rot and powdery mildew of strawberry in large plastic tunnel and field production systems. Plant Dis. 85:901-909.

$\mathrm{Xu}, \mathrm{X}$., Robinson, J., Jeger, M., and Jeffries, P. 2010. Using combination of biocontrol agents to control Botrytis cinerea on strawberry leaves under fluctuating temperatures. Biocontrol Sci. Technol. 20:359-373. 